This item was submitted to Loughborough's Research Repository by the author.

Items in Figshare are protected by copyright, with all rights reserved, unless otherwise indicated.

\title{
Creep behaviour of cracked high performance fibre reinforced concrete beams under flexural load
}

PLEASE CITE THE PUBLISHED VERSION

https://doi.org/10.1007/978-94-024-1001-3_10

\section{PUBLISHER}

Springer (@ Rilem)

VERSION

AM (Accepted Manuscript)

\section{PUBLISHER STATEMENT}

This work is made available according to the conditions of the Creative Commons Attribution-NonCommercialNoDerivatives 4.0 International (CC BY-NC-ND 4.0) licence. Full details of this licence are available at: https://creativecommons.org/licenses/by-nc-nd/4.0/

\section{LICENCE}

CC BY-NC-ND 4.0

\section{REPOSITORY RECORD}

Galeote, Eduardo, Ana Blanco, Albert De la Fuente, and Sergio H. Cavalaro. 2019. "Creep Behaviour of Cracked High Performance Fibre Reinforced Concrete Beams Under Flexural Load”. figshare. https://hdl.handle.net/2134/32344. 


\title{
CREEP BEHAVIOUR OF CRACKED HIGH PERFORMANCE FIBRE REINFORCED CONCRETE BEAMS UNDER FLEXURAL LOAD
}

\author{
Eduardo Galeote $^{(1)}$, Ana Blanco ${ }^{(1)}$, Albert de la Fuente ${ }^{(1)}$ and Sergio H.P. Cavalaro ${ }^{(1)}$. \\ ${ }^{(1)}$ Department of Civil and Environmental Engineering, Universitat Politècnica de Catalunya, Spain.
}

\begin{abstract}
The investigation on flexural creep of high performance fibre reinforced concrete (HPFRC) is still scarce. Even though the presence of fibres in concrete help to control the deformations, these may increase under the effect of a sustained load. To analyse the effect of creep in pre-cracked HPFRC elements, twelve beams reinforced with either glass or steel fibres with dimensions $40 \times 80 \times 1200$ $\mathrm{mm}$ were tested under a three-point configuration. For that, a new type of frame was designed and constructed to test the HPFRC beams under flexural load in a climate-controlled room with constant temperature and relative humidity. The loading mechanism was based on a lever system, applying sustained load ranging between $25 \%$ and $50 \%$ of the load at which the first crack appeared. The deflection at the mid-span was registered by means of LVDT transducers. Additionally, the influence of the curing procedure (with or without aluminium tape wrap) was assessed. In general, glass fibre reinforced beams presented higher deflections than steel fibres, even though at low load levels the type of fibre did not have significant influence on the deformation.
\end{abstract}

Keywords: HPFRC, creep, steel fibres, glass fibres, flexural load.

\section{INTRODUCTION}

High performance fibre reinforced concrete (HPFRC) represents an important innovation in the field of construction materials with a high potential of application [1]. The inherent brittleness of the matrix of this type of concrete may be partly compensated by the addition of fibres, which allows increasing ductility at the cracked state depending on the type and content of fibres used.

The effect of creep in concrete is of paramount importance and should not be ignored in design since extreme deformations can compromise serviceability [2]. Unfortunately, there is not a specific criterion to evaluate this effect neither in guidelines nor in codes. The lack of a unified methodology hinders the analysis of results already published due to the significant differences on the methods used. Besides, the long time required to evaluate creep makes its research less common due to the difficulty in obtaining results. However, some studies about creep may be found in both cracked and non-cracked sections in fibre reinforced concrete (FRC) [3-5].

The main aim of this research was to develop a new method capable of measuring the deformation produced by creep in slender elements. For this reason, a steel frame able to hold up to 12 beams was designed and constructed. This structure is based on a system of levers to transmit the 
load to the mid-span of the beams and includes an acquisition data system to measure the deflection at the central section of the beam. The primary advantage is that this structure enables to load and measure the deformation of each beam individually. Such a type of frame allows to independently customize the load to test each beam without interfering on the others.

An experimental program was conducted to analyse both the performance of the structure and the creep in HPFRC beams. The analysis of creep involved the manufacturing and testing of 12 beams with a height of $40 \mathrm{~mm}$, a width of $80 \mathrm{~mm}$ and a length of $1200 \mathrm{~mm}$ with two different types of fibre reinforcement and two different curing processes in a pre-cracked state. Additionally, and as a result of the post-peak behaviour of the beams during the pre-cracking process, different load levels were applied onto the beams.

\section{DESIGN OF THE FRAME}

One of the main goals pursued in the design of the new frame was that each beam could be loaded individually. Unlike other test setups previously proposed $[6,7]$ in which a column for three beams was designed, the solution here presented required more space since the beams were not piled but placed one next to another. Some initial estimations displayed a strength of the concrete at the midspan high enough to think about using a system of levers to transmit and easily handle the loads. Moreover, the creep was evaluated by means of the deflection instead of measuring the crack opening or both parameters $[5,8]$.

The steel frame (Figure 1) was designed to measure the creep of 12 beams at the same time. The frame consists of a system based on a three-point configuration with a distance between supports of $1100 \mathrm{~mm}$ (Figure 2b). A hollow steel cylinder was placed at the centre of the upper face of each beam together with a steel sheet. Fixed to the frame, an aluminium structure above the levers and the beams is used to hold the LVDTs to measure the deflection of the beams. These LVDTs are in direct contact with the steel sheets in the centre of the beams (Figure 2c) and connected to a data acquisition system.

At the vertical columns, hollow steel bars of $22 \mathrm{~mm}$ of diameter were installed crosswise to produce the effect of a hinge mechanism to the levers as depicted in Figure 2d. The levers were fixed to these bars at one edge and were free at the opposite edge, allowing the rotation around the longitudinal axis of the steel bar. To transmit the load to the beams, the levers rest on the steel cylinders fixed to the beams while the loads are placed on the free edge of the steel beam as shown in Figure 2e.

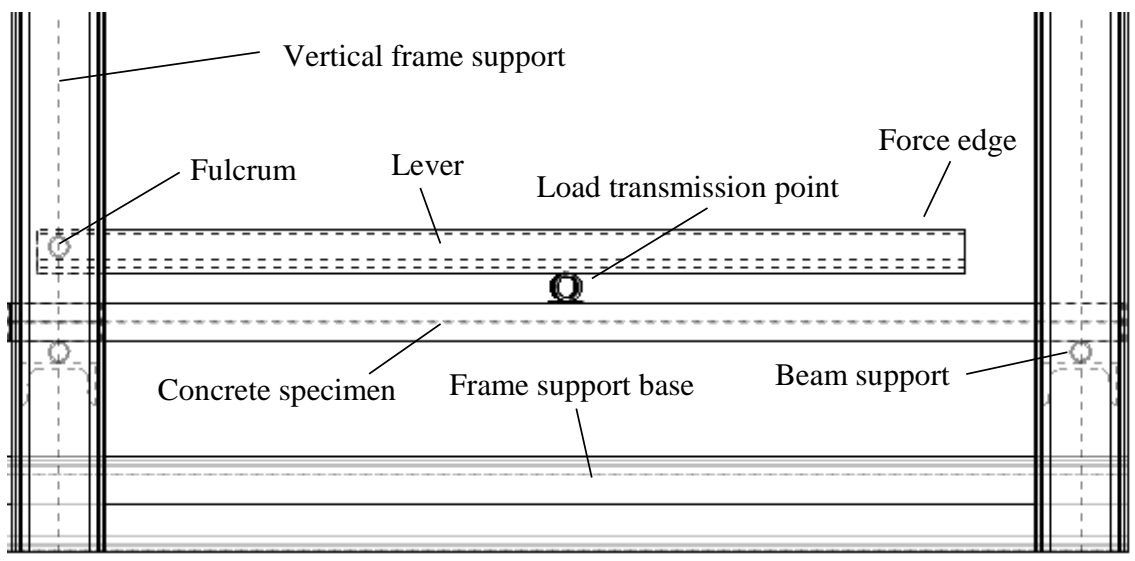

Figure 1. Schematic representation of the frame for the creep test. 

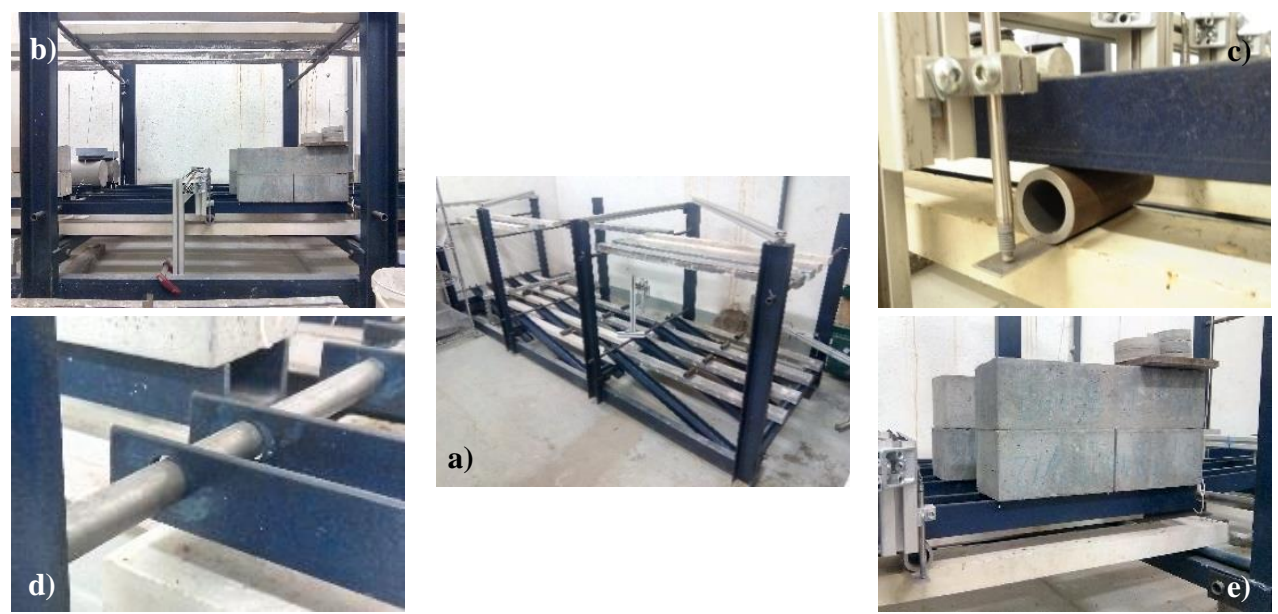

Figure 2: a) Steel frame, b) three-point configuration 1100mm length, c) hollow cylinder with LVDT transducer, d) hinge mechanism and e) load on lever.

\section{EXPERIMENTAL PROGRAM}

\subsection{Materials and concrete mix}

Two series of concrete were produced following the same mixing procedure. The type of fibre, after which the mixes were named, was the main difference between the two series manufactured. SF contained $150 \mathrm{~kg} / \mathrm{m}^{3}$ of steel fibres, whereas GF had $44 \mathrm{~kg} / \mathrm{m}^{3}$ of glass fibres. These two contents of fibres represent a volume of $1.9 \%$ in SF and $1.6 \%$ in GF with respect to the total concrete volume. Further details about the proportioning of the mixes and the properties of the fibres are presented in Table 1 and 2, respectively.

Table 1: Mix proportioning of concrete

\begin{tabular}{lll}
\hline Material & $\begin{array}{l}\mathrm{SF} \\
{\left[\mathrm{kg} / \mathrm{m}^{3}\right]}\end{array}$ & $\begin{array}{l}\mathrm{GF} \\
{\left[\mathrm{kg} / \mathrm{m}^{3}\right]}\end{array}$ \\
\hline Cement 52,5R & 800 & 800 \\
Silica sand 0/2 & 1161 & 1161 \\
Filler $\left(\mathrm{CaCO}_{3}\right)$ & 200 & 200 \\
Water & 228 & 236 \\
Nanosilica & 40 & 40 \\
Superplasticizer & 30 & 30 \\
Steel fibres & 150 & - \\
Glass fibres & - & 44 \\
\hline
\end{tabular}


Table 2: Properties of the fibres

\begin{tabular}{lll}
\hline Characteristics & Steel fibres & Glass fibres \\
\hline Geometry & Straight & Filament \\
Length $[\mathrm{mm}]$ & 13 & 13 \\
Diameter [mm] & 0.2 & 0.018 \\
Tensile strength [MPa] & $2300-2500$ & 1400 \\
Elastic modulus [GPa] & 210 & 74 \\
Specific weight $\left[\mathrm{g} / \mathrm{cm}^{3}\right]$ & $7.75-8.05$ & 2.7 \\
\hline
\end{tabular}

The characterization of the material involved the elastic modulus $\left(E_{c m}\right)$, which was determined according with [9] in 4 cylindrical specimens of $\phi 150 \times 300 \mathrm{~mm}$. The compressive strength $\left(f_{c m}\right)$ was tested according with [10] in 4 cubic specimens of $150 \times 150 \mathrm{~mm}$ and the residual tensile strength $\left(f_{R 1}, f_{R 2}, f_{R 3}\right.$ and $\left.f_{R 4}\right)$ was assessed by means of the three-point bending test in specimens of $150 \mathrm{x}$ $150 \times 600 \mathrm{~mm}$ according with [11]. Table 3 presents the average results of these tests together with the coefficient of variation (CV).

Table 3: Average mechanical properties of the concrete

\begin{tabular}{llllll}
\hline Parameters & \multicolumn{1}{l}{$\mathrm{SF}$} & & & $\mathrm{GF}$ \\
\cline { 2 - 3 } \cline { 5 - 6 }$[\mathrm{MPa}]$ & Average & $\mathrm{CV}$ & & Average & $\mathrm{CV}$ \\
\hline $\mathrm{E}_{\mathrm{cm}}$ & 34970 & $3.16 \%$ & & 31137 & $2.72 \%$ \\
$\mathrm{f}_{\mathrm{cm}}$ & 102.79 & $1.54 \%$ & & 73.59 & $3.14 \%$ \\
$\mathrm{f}_{\mathrm{LOP}}$ & 7.24 & $16.59 \%$ & & 7.68 & $11.02 \%$ \\
$\mathrm{f}_{\mathrm{R} 1}$ & 10.41 & $9.36 \%$ & & 5.03 & $15.20 \%$ \\
$\mathrm{f}_{\mathrm{R} 2}$ & 9.79 & $8.63 \%$ & & 1.77 & $14.41 \%$ \\
$\mathrm{f}_{\mathrm{R} 3}$ & 8.13 & $8.88 \%$ & & 0.82 & $13.96 \%$ \\
$\mathrm{f}_{\mathrm{R} 4}$ & 6.95 & $11.32 \%$ & & 0.46 & $18.47 \%$ \\
\hline
\end{tabular}

Even though both concrete compositions were similar, a big difference in the compressive strength was detected. This effect might be attributed to higher air content in the GF mix compared with the SF series. Moreover, taking into account the diameter, specific weight and the different contents of fibres, the amount of glass fibres was about 100 times higher than steel fibres. This led to more interfacial transition zones which affected the compressive strength.

To analyse the effect of creep, 12 beams of $40 \times 80 \times 1200 \mathrm{~mm}$ per each dosage were manufactured. The concrete was produced in a vertical axis mixer and directly poured from the skip to the moulds (Figure 3a). To prevent the loss of superficial water and a consequent early shrinkage a curing layer was sprayed over the free surface of the concrete. All the specimens were demoulded 24 $\mathrm{h}$ after the fabrication and were immediately stored in a moist room with a controlled temperature of $20{ }^{\circ} \mathrm{C}$ and a relative humidity of $100 \%$ (Figure $3 \mathrm{~b}$ ). Half of the beams corresponding to each series were wrapped in aluminium tape to analyse the influence of restricting the humidity transfer during the curing. 

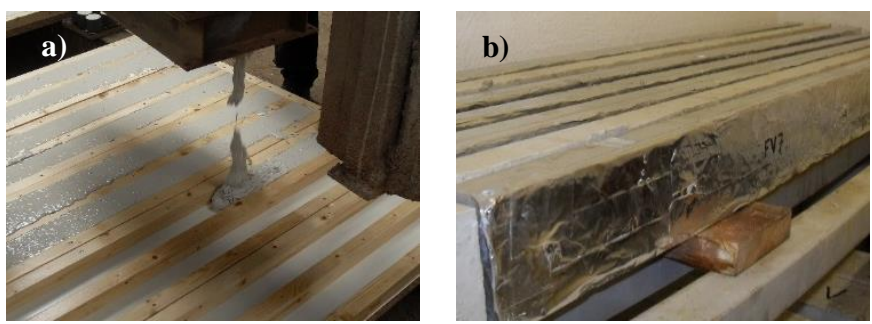

Figure 3: a) Pouring of the beams and b) wrapped beam in moist room

\subsection{Pre-cracking and loading sequence}

The beams were pre-cracked applying load at the mid-span according to the three-point test setup as depicted in Figure 4. Notches were not performed to avoid reduction of the section. The distance between supports was $500 \mathrm{~mm}$ and the load was transmitted to the beam at a constant rate of 0.3 $\mathrm{mm} / \mathrm{min}$. When the beam reached the flexural strength, the loading operation was immediately stopped. This point was identified by means of both the load-displacement slope variation and the load dropping occurred at that instant. Even though the common procedure in creep tests is arriving to a certain crack width or deflection [6], the procedure here described was systematically followed for all specimens. Moreover, it is worth to mention that no additional damage was undergone by any sample, since in no case the deflection exceeded $1 \mathrm{~mm}$.

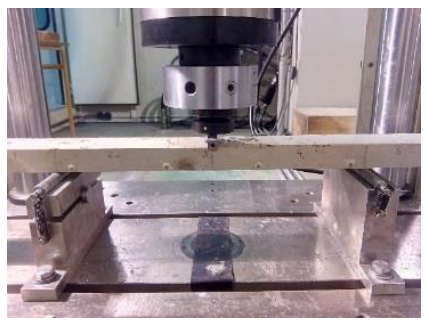

Figure 4: Pre-cracking of the beam in a three-point configuration

Since the span changed from $500 \mathrm{~mm}$ at the load press to $1100 \mathrm{~mm}$ at the frame, the loads $P$ in each case needed to be recalculated as described in Equation 1 by keeping the bending moment constant for both lengths. As a result, the load to produce the same moment in the beam of $1100 \mathrm{~mm}$ decreased with respect to the load for a beam of $500 \mathrm{~mm}$.

$P_{1100 \mathrm{~mm}}=\frac{l_{500 \mathrm{~mm}}}{l_{1100 \mathrm{~mm}}} \cdot P_{500 \mathrm{~mm}}$

Nevertheless, a different behaviour between wrapped and non-wrapped specimens after the crack strength was detected. In non-wrapped specimens there was a small drop of the strength after the crack load, followed by an increase of the strength even over the peak. In wrapped specimens a sudden drop of the load occurred immediately after the peak load was reached, showing no significant increase of the load from this point onwards. Moreover, higher peak values were obtained in wrapped beams, possibly due to the additional effect of the aluminium since it was not removed.

As a result, two different strategies were defined for loading the beams during the creep test depending on whether the beams were wrapped or non-wrapped. As depicted in the schemes of Table 4 , the reference load for non-wrapped specimens was the cracking load $\left(P_{c r}\right)$, whereas for wrapped 
specimens the reference load was that in which the major cracks stabilize and the residual strength appears $\left(P_{c r}^{*}\right)$. The load for each beam in the creep test was calculated on the basis of these data.

For non-wrapped specimens the creep load was defined as 50\% of $P_{c r}$ from the beginning of the test, and no changes on the load were later performed. Wrapped specimens were initially loaded at $25 \%$ of $P_{c r}^{*}$ and after a period of 15 days, the load was changed to $35 \%$ of $P_{c r}^{*}$. An exception was made with GF6, which was initially loaded with $50 \%$ of $P_{c r}$ but immediately collapsed. At 30 days, to compare the creep between non-wrapped and wrapped beams, the creep load of steel fibre reinforced wrapped beams was pushed to the limit and it was increased to $50 \%$ of $P_{c r}$.

Table 4: Different load levels $[\mathrm{kN}]$ in non-wrapped and wrapped HPFRC beams

\begin{tabular}{|c|c|c|c|c|c|c|c|}
\hline \multirow{2}{*}{\multicolumn{2}{|c|}{ Scheme }} & \multirow[t]{2}{*}{ Beam } & \multicolumn{2}{|c|}{$\mathrm{L}=500 \mathrm{~mm}$} & \multicolumn{3}{|c|}{$\mathrm{L}=1100 \mathrm{~mm}$} \\
\hline & & & $\mathrm{P}_{\mathrm{cr}}$ & $\mathrm{P}_{\mathrm{cr}}^{*}$ & $\mathrm{t}_{0}(0$ days $)$ & $\mathrm{t}_{1}$ (15 days) & $\mathrm{t}_{2}$ (30 days) \\
\hline \multirow{6}{*}{ 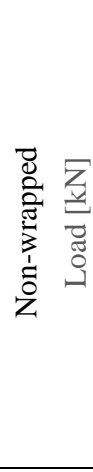 } & \multirow{6}{*}{$P_{c r}$} & SF1 & 1.43 & - & $\begin{array}{l}0.33 \\
\left(50 \% P_{c r}\right)\end{array}$ & - & - \\
\hline & & $\mathrm{SF} 2$ & 1.93 & - & $\begin{array}{l}0.44 \\
\left(50 \% P_{c r}\right)\end{array}$ & - & - \\
\hline & & SF3 & 1.61 & - & $\begin{array}{l}0.37 \\
\left(50 \% P_{c r}\right)\end{array}$ & - & - \\
\hline & & GF1 & 1.33 & - & $\begin{array}{l}0.30 \\
\left(50 \% P_{c r}\right)\end{array}$ & - & - \\
\hline & & GF2 & 1.33 & - & $\begin{array}{l}0.30 \\
\left(50 \% P_{c r}\right)\end{array}$ & - & - \\
\hline & & GF3 & 1.52 & - & $\begin{array}{l}0.34 \\
\left(50 \% P_{c r}\right)\end{array}$ & - & - \\
\hline \multirow{6}{*}{ 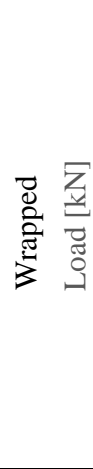 } & \multirow[b]{6}{*}{ Displacement [mm] } & SF6 & 2.29 & 1.25 & $\begin{array}{l}0.14 \\
\left(25 \% P_{c r}^{*}\right)\end{array}$ & $\begin{array}{l}0.20 \\
\left(35 \% P_{c r}^{*}\right)\end{array}$ & $\begin{array}{l}0.52 \\
\left(50 \% P_{c r}\right)\end{array}$ \\
\hline & & SF7 & 2.57 & 1.49 & $\begin{array}{l}0.17 \\
\left(25 \% P_{c r}^{*}\right)\end{array}$ & $\begin{array}{l}0.23 \\
\left(35 \% P_{c r}^{*}\right)\end{array}$ & $\begin{array}{l}0.58 \\
\left(50 \% P_{c r}\right)\end{array}$ \\
\hline & & SF8 & 2.49 & 1.58 & $\begin{array}{l}0.18 \\
\left(25 \% P_{c r}^{*}\right)\end{array}$ & $\begin{array}{l}0.24 \\
\left(35 \% P_{c r}^{*}\right)\end{array}$ & $\begin{array}{l}0.57 \\
\left(50 \% P_{c r}\right)\end{array}$ \\
\hline & & GF6 & 1.86 & 0.80 & $\begin{array}{l}0.42 \\
\left(50 \% P_{c r}\right)\end{array}$ & - & - \\
\hline & & GF7 & 2.19 & 1.46 & $\begin{array}{l}0.17 \\
\left(25 \% P_{c r}^{*}\right)\end{array}$ & $\begin{array}{l}0.23 \\
\left(35 \% P_{c r}^{*}\right)\end{array}$ & - \\
\hline & & GF8 & 1.79 & 1.00 & $\begin{array}{l}0.12 \\
\left(25 \% P_{c r}^{*}\right)\end{array}$ & $\begin{array}{l}0.16 \\
\left(35 \% P_{c r}^{*}\right)\end{array}$ & - \\
\hline
\end{tabular}

\section{RESULTS}

Creep was evaluated measuring the vertical displacement at the mid-span of the beams. In this section, the evolution of the deflection and the evolution of the creep coefficient are analysed. The differences on these two parameters are discussed according to the influence of the type of fibre and curing method.

\subsection{Evolution of the deflection}

The total deflection at a time $t, \delta_{t o t}(t)$, is the direct sum of the initial deflection, $\delta\left(t_{o}\right)$, due to the instant effect of the loading of the beams and the deflection due to creep $\delta_{\varphi}(t)$. In Figure 5 it is shown 
the deflection due to creep of each beam with steel fibres (SF) or glass fibres (GF), as well as their average value. The results also reveal the differences between non-wrapped and wrapped specimens. The data of non-wrapped beams are shown for a time of 150 days as no changes on the load level were introduced within that period. In wrapped specimens the level loads were changed two times. Only data until the day 30 appear, since during that period the two level loads were the same for both types of fibre.
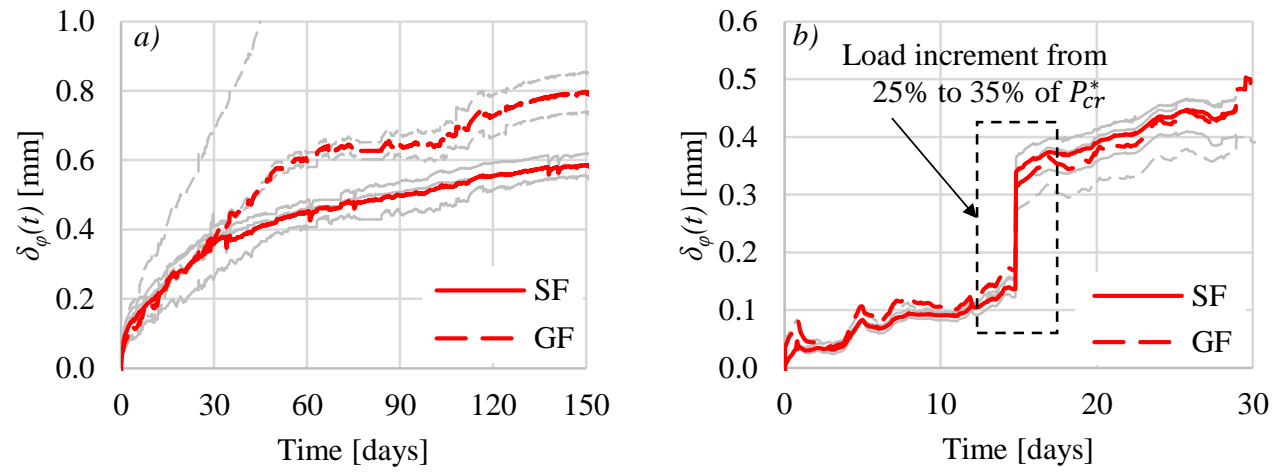

Figure 5: Average creep deflection in a) non-wrapped and b) wrapped beams

Figure 5a indicates that both SF and GF present a similar $\delta_{\varphi}(t)$ until the day 30. At this point, when the deflection in GF is only $2.9 \%$ higher than in SF, the trend starts to change and the deflection detected in the GF beams gradually increases with respect to SF. At 150 days, the deflection due to creep in GF is $36 \%$ higher than in SF. These results highlight that the biggest differences between the two types of fibres in terms of $\delta_{\varphi}(t)$ are evident from 30 days onwards.

One of the beams reinforced with glass fibres (GF2) revealed an unexpected behaviour. Since the beginning of the test the deflection was significantly higher than the deflection of the other GF beams. This inconsistency with respect to the other results may be due to a defective manufacture of this individual beam, since its pre-cracking and loading procedure was identical to the rest of the beams.

The performance of wrapped specimens is gathered in Figure $5 \mathrm{~b}$. As it happened in non-wrapped specimens, the average deflection of the beams resulted to be very similar regardless of the type of fibre used as reinforcement. Moreover, when the load was increased at the day 15 from $25 \%$ to $35 \%$ of $P_{c r}^{*}$ the deflection in SF increased from 0.136 to $0.338 \mathrm{~mm}$, whereas in GF this grew from 0.169 to $0.306 \mathrm{~mm}$. At 30 days, the average difference of $\delta_{\varphi}(t)$ between beams with SF and GF was only $1 \%$, thus excluding the type of fibre as a factor influencing the deflection in such low load levels. Further study should be undertaken to identify at which load level the fibres become the distinguishing feature affecting $\delta_{\varphi}(t)$.

Comparing the results gathered in Table 5 regarding the curing method between beams, it was noticed that $\delta_{\varphi}(t)$ at 15 and 30 days was higher in wrapped specimens when the load level was $35 \%$ of $P_{c r}^{*}$. At 15 days, the deflection due to creep in SF and GF was $25 \%$ and $21 \%$ higher than in nonwrapped specimens, respectively. At 30 days, these percentages decreased respectively to $19 \%$ and $17 \%$, still remaining the deflection in wrapped specimens greater than in non-wrapped.

The latter results seem to be contradictory in relation to the load level since the load in wrapped specimens was in every case lower than in non-wrapped. This could be attributed to the different curing process produced by the lack of external water contribution during the set of concrete. This might have caused a lower amount of hydrated cement paste and, consequently, a lower elastic 
modulus. In this case, deformation would be greater in wrapped specimens in comparison to others with a higher degree of hydration and higher elastic modulus.

Table 5: Deflection due to creep at 15 and 30 days

\begin{tabular}{llllll}
\hline \multirow{2}{*}{$\begin{array}{l}\text { Deflection } \\
{[\mathrm{mm}]}\end{array}$} & \multicolumn{2}{l}{ Non-wrapped $\left(50 \% P_{c r}\right)$} & & \multicolumn{2}{l}{ Wrapped $\left(35 \% P_{c r}^{*}\right)$} \\
\cline { 2 - 3 } \cline { 6 - 6 } & $\mathrm{SF}$ & $\mathrm{GF}$ & & $\mathrm{SF}$ & $\mathrm{GF}$ \\
\hline$\delta_{\varphi}(15)$ & 0.254 & 0.241 & & 0.338 & 0.306 \\
$\delta_{\varphi}(30)$ & 0.363 & 0.374 & & 0.447 & 0.452 \\
\hline
\end{tabular}

\subsection{Evolution of the creep coefficient}

The creep coefficient at a defined time $t, \varphi_{c}(t)$, may be calculated as the ratio between the deflection produced by creep $\delta_{\varphi}(t)$ and $\delta\left(t_{o}\right)$, as indicated in Equation 2. Although this is not the classical formulation of creep, previous studies report the possibility of determining the creep coefficient in this way when the deformation is not directly measured.

$\varphi_{c}(t)=\frac{\delta_{\varphi}(t)}{\delta\left(t_{0}\right)}$

Table 6 summarizes the creep coefficients at 15, 30, 90 and 150 days as well as the increments between these periods of time and Figure 6 shows the whole evolution of the creep coefficient through time. The results of the beams presented in Table 6 correspond to the specimens without aluminium wrapping and did not suffer any load variations during the creep test. No results of GF2 are available from the day 47 onwards as a result of its failure.

Table 6: Creep coefficients in non-wrapped beams

\begin{tabular}{llllllll}
\hline Beam & $\varphi_{c}(15)$ & $\varphi_{c}(30)$ & $\varphi_{c}(90)$ & $\varphi_{c}(150)$ & $\varphi_{c}(15-30)$ & $\varphi_{c}(30-90)$ & $\varphi_{c}(90-150)$ \\
\hline SF1 & 0.25 & 0.35 & 0.61 & 0.75 & $44.5 \%$ & $71.3 \%$ & $23.6 \%$ \\
SF2 & 0.26 & 0.36 & 0.47 & 0.54 & $39.2 \%$ & $31.5 \%$ & $15.0 \%$ \\
SF3 & 0.21 & 0.30 & 0.37 & 0.42 & $41.5 \%$ & $23.9 \%$ & $15.1 \%$ \\
GF1 & 0.71 & 1.09 & 1.88 & 2.27 & $52.9 \%$ & $72.4 \%$ & $20.8 \%$ \\
GF2 & 0.45 & 0.73 & - & - & $61.8 \%$ & - & - \\
GF3 & 0.26 & 0.40 & 0.70 & 0.88 & $50.4 \%$ & $75.4 \%$ & $26.0 \%$ \\
\hline
\end{tabular}

The values of the creep coefficient were found to be in all cases higher in glass fibre reinforced beams than in steel fibre beams. At the day 15, GF3 presented the lowest creep coefficient of glass fibre beams, which was the same as the highest creep coefficient of steel fibres obtained in SF2. As reported in previous investigations [12], this effect may be attributed to the different elastic modulus of the two different concretes, since the higher capacity of deformation of glass fibres is a result of the lower elastic modulus and tensile strength when compared to steel fibres (see Table 2).

In the case of SF, the greatest increments of the creep coefficient were produced between the days 15 and 30, whereas in GF the biggest increment occurred between the days 30 and 90 . Nevertheless, in both types of beam, from the day 90 the creep coefficient reduces its value and the increments between 90 and 150 days experience a drop in comparison with those obtained for 30-90 days. Longer periods for the creep test would provide further information to make long term predictions and consider the possibility of sudden failure of fibres. 

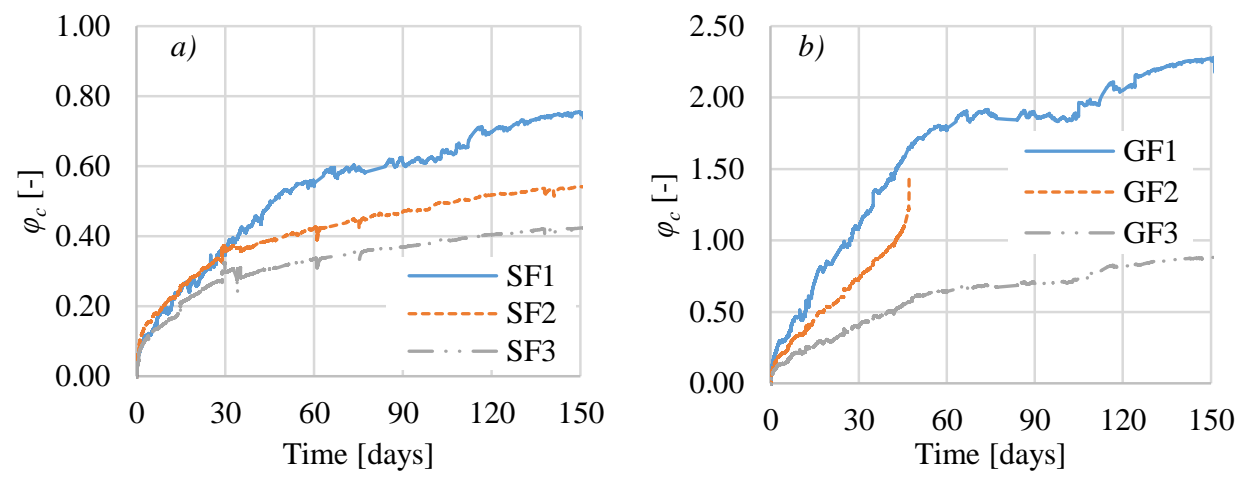

Figure 6: Relationship between time and creep coefficient in non-wrapped beams.

The variability in the results between beams is also noticeable. The variation of the creep coefficient in SF for days 15 and 30 was around $10 \%$, whereas the CV in GF at the same days was approximately $47 \%$. These CV increased at days 90 and 150, achieving an average value of $27 \%$ in $\mathrm{SF}$ and $63 \%$ in GF.

The creep coefficients of the wrapped beams are shown in Table 7 and their evolution during the test including the load changes in Figure 7. Regarding the values gathered in Table 7, given that these beams experienced different load levels, the creep coefficients are shown with respect to the load level at which they were obtained. At days 15 and 30 two coefficients are presented since those were the days when the load levels were changed. Two additional coefficients (days 90 and 150) are also presented, these only for GF yet beams with SF collapsed between 2 and 4 days after the load was increased to $50 \%$ of $P_{c r}$ at the day 30 .

Table 7: Creep coefficients in wrapped beams

\begin{tabular}{lllllll}
\hline Beam & $\begin{array}{l}\varphi_{c}(15) \\
\left(25 \% P_{c r}^{*}\right)\end{array}$ & $\begin{array}{l}\varphi_{c}(15) \\
\left(35 \% P_{c r}^{*}\right)\end{array}$ & $\begin{array}{l}\varphi_{c}(30) \\
\left(35 \% P_{c r}^{*}\right)\end{array}$ & $\begin{array}{l}\varphi_{c}(30) \\
\left(50 \% P_{c r}\right)\end{array}$ & $\begin{array}{l}\varphi_{c}(90) \\
\left(35 \% P_{c r}^{*}\right)\end{array}$ & $\begin{array}{l}\varphi_{c}(150) \\
\left(35 \% P_{c r}^{*}\right)\end{array}$ \\
\hline SF6 & 0.19 & 0.50 & 0.63 & 2.63 & - & - \\
SF7 & 0.24 & 0.65 & 0.85 & 3.51 & - & - \\
SF8 & 0.35 & 0.77 & 1.08 & 3.30 & - & - \\
GF7 & 0.58 & 1.10 & 1.67 & - & 2.12 & 1.73 \\
GF8 & 0.52 & 0.89 & 1.27 & - & 1.38 & 1.17 \\
\hline
\end{tabular}

The creep coefficient at 15 days for the same load level was in average two times roughly higher in GF than in SF. At 15 and 30 days with a load level of $35 \% P_{c r}^{*}, \varphi_{c}$ of GF was found to be again higher than the coefficient for SF. The coefficient kept growing but at 150 days it decreased around $16 \%$ in comparison with the value obtained at 90 days.

However, the biggest increments were detected at the load level changes rather than those produced as a result of the creep. An example of this situation is GF6, which accidentally failed as a result of an excessive load level. Regarding the rest of the beams, an increase of the load from $25 \%$ of $P_{c r}^{*}$ to $35 \%$ produced a boost of around $150 \%$ in SF, whereas for GF that percentage was approximately $80 \%$. When in SF the load was changed at the day 30 to $50 \%$ of $P_{c r}$ the increments 
were of 315\% in SF6-SF7 and 206\% in SF8, producing the collapse of the beams between 2 and 4 days later.
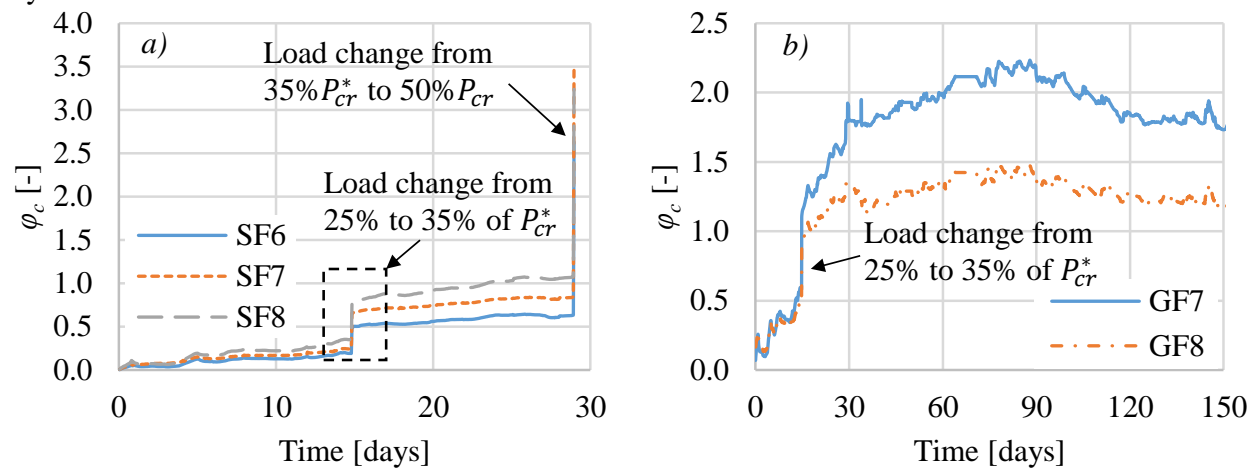

Figure 7: Evolution of creep coefficient in wrapped beams.

\section{CONCLUSIONS}

The main goal of the current study was to design and evaluate a new type of frame to analyse creep in HPFRC. Additionally, 12 HPFRC beams were tested measuring the deflection at the mid-span in a pre-cracked state. Based on the performance of the frame designed and constructed and the results obtained during the creep test, several conclusions may be drawn:

- A new frame to analyse the flexural creep of FRC elements has been conceived, this allowing the possibility of testing at the same time several elements.

- It was confirmed that the load of each beam may be individually customized without interfering on the other specimens. This allows studying several variables such as the type of fibre or the load level of each individual specimen.

- The experimental campaign conducted verified the applicability of the frame on testing creep in HPFRC beams. The loads were able to be kept constant during all the test period of time and they could also be changed when necessary to adapt new load levels.

- The load level should be stablished depending on the behaviour after the flexural strength to avoid sudden collapse. Beams curing without external contribution of water presented lower residual strength and, therefore, the load level had to be reduced.

- At low load levels (25-35\% $\left.P_{c r}^{*}\right)$ the type of fibre had no significant effect on the deflection. Not even the increase of the load level from $25 \%$ to $35 \% P_{c r}^{*}$ produced notable differences between the types of fibre reinforcement.

- The deflection in wrapped specimens was higher than in non-wrapped. This was reflected at the case when wrapped specimens were loaded with $35 \% P_{c r}^{*}$ and the load in non-wrapped was $50 \%$ of $P_{c r}$.

- The creep coefficient in GF was in all cases higher than in SF. This might be a consequence of the lower residual strength $\left(f_{R i}\right)$ in GF.

\section{ACKNOWLEDGEMENTS}

The authors acknowledge the collaboration of ESCOFET S.A. in the performance of the experimental program. The first author also acknowledges the grant FPU provided by the Spanish Ministry of Education, Culture and Sports. 


\section{REFERENCES}

[1] Walraven, J., 'High performance fiber reinforced concrete: progress in knowledge and design codes', Mater. Struct. 42 (9) (2009) 1274-1260.

[2] Bernard, E. S., 'Creep of cracked fibre reinforced shotcrete panels', in 'Shotcrete: More Engineering Developments', Proceedings of the Second International Conference on Engineering in Shotcrete, Cairns, Australia, 2004 (Taylor \& Francis Group, London, 2004) 47 57.

[3] Barragán, B. E. and Zerbino, R. L., 'Creep behaviour of cracked steel fibre reinforced concrete beams', Proceedings of the $7^{\text {th }}$ International RILEM Symposium on Fibre Reinforced Concrete: Design and Applications (BEFIB 2008), Chennai, India (2008) 577-586.

[4] Serna Ros, P., Bossio, M. E., Zerbino, R. and Martí Vargas, J. R., 'Fluencia y propiedades residuales de hormigones autocompactantes con fibras expuestos en estado fisurado a diferentes condiciones ambientales', $3^{\circ}$ Congreso Iberoamericano sobre hormigón autocompactante (2012) 221-230.

[5] Abrishambaf, A., Barros, J. A. O. and Cunha, V. M. C. F., 'Time-dependent flexural behaviour of cracked steel fibre reinforced self-compacting concrete panels', Cem. Conc. Res. 72 (2015) 21-36.

[6] Arango, S. E., Serna, P., Martí-Vargas, J. R. and García-Taengua, E., 'A test method to characterize flexural creep behaviour of pre-cracked FRC specimens', Exp. Mech. 52 (8) (2012) 1067-1078.

[7] Pujadas, P., 'Caracterización y diseño del hormigón reforzado con fibras plásticas', PhD. Thesis, Universitat Politècnica de Catalunya (2013).

[8] Blanco, A., 'Characterization and modelling of SFRC elements', PhD. Thesis, Universitat Politècnica de Catalunya (2013).

[9] CEN, 'EN 12390-13:2014. Testing hardened concrete - Part 13: Determination of secant modulus of elasticity in compression', European Committee for Standardization (Brussels, 2014).

[10] CEN, 'EN 12390-3:2009. Testing hardened concrete - Part 3: Compressive strength of test specimens', European Committee for Standardization (Brussels, 2009).

[11] CEN, 'EN 14651:2007. Test method for metallic fibre concrete. Measuring the flexural tensile strength (limit of proportionality (LOP), residual)', European Committee for Standardization (Brussels, 2007).

[12] Zhao, O., Yu, J., Geng, G., Jiang, J. and Liu, X., 'Effect of fiber types on creep behavior of concrete', Constr. Build. Mater. 105 (2016) 416-422.

[13] Abrishambaf, A., Barros, J. A. O. and Cunha, V. M. C. F., 'Relation between fibre distribution and post-cracking behaviour in steel fibre reinforced self-compacting concrete panels', Cem. Conc. Res. 51 (2013) 57-66. 